\title{
Efficient high-resolution 3-D interpolation of meteorological variables for operational use
}

\author{
C. Lussana ${ }^{1}$, M. R. Salvati ${ }^{1}$, U. Pellegrini ${ }^{1}$, and F. Uboldi ${ }^{2}$ \\ ${ }^{1}$ ARPA Lombardia, Milano, Italy \\ ${ }^{2}$ Consultant, Novate Milanese, Italy
}

Received: 19 December 2008 - Revised: 7 June 2009 - Accepted: 8 June 2009 - Published: 5 August 2009

\begin{abstract}
In recent years, the use of mesoscale meteorological network data has been growing. An Optimal Interpolation (OI) method is used to interpolate on a regular grid the hourly averaged values of temperature, relative humidity, wind vector, atmospheric pressure, and hourly cumulated precipitation. For all variables, except precipitation, the background (i.e. first guess) information is obtained by detrending the observations using the geographical parameters. For precipitation, the M. Lema radar-derived best estimate of precipitation rate at the ground is used. The characteristics of the OI schemes are shown in several test cases using data from ARPA Lombardia's mesoscale meteorological network. Finally, a quantitative diagnostics for temperature and relative humidity is carried out by using Cross Validation (CV) scores computed with large sets of data.
\end{abstract}

\section{Introduction}

This document describes a spatial interpolation scheme based on Optimal Interpolation (OI; Gandin, 1963) applied to the data collected by a mesoscale meteorological network. $\mathrm{OI}$ is a method widely used in meteorology and climatology and it is based on a linear combination of the observed values with a background field weighting their respective uncertainties. For a review of OI and its comparison with other data interpolation techniques see for example Daley (1991) and Kalnay (2003). In the presented work, the analyzed fields are mostly intended as support to nowcasting and forecasting in an operational meteorological centre. Forecasters require easy access to several different variables to gain better insight into meteorological phenomena: for this reason the OI is applied to hourly averaged observations of temperature, wind, relative humidity, pressure, and to the hourly cumulated precipitation.

The observing system is ARPA Lombardia's mesoscale meteorological network, managed by the local public weather service. The meteorological network is characterized by a high space and time resolution of observations (automatic stations), but with strong inhomogeneities in sensors' distribution. As an example, Fig. 1 shows raingauges and anemometers observation locations. Lombardy itself is char- acterized by a very complex orography and by different land uses: the representativity component of the observational error plays an important role and must be properly handled.

The interpolation is performed over a regular grid. The spatial domain measures roughly $200 \mathrm{~km} \times 200 \mathrm{~km}$. A grid resolution of $1.5 \mathrm{~km}$ has been chosen: it is the coarser resolution that can be used without having significant differences between grid and station elevation. It is worth remarking that it is the grid resolution that accounts for most of the topographic detail of the analysis maps, and that the grid resolution is higher than the observation network resolution.

About three years of operational use have proven the algorithm to be efficient (in using computer resources) and stable (with respect to the observing system's anomalies or malfunctionings). Furthermore, the OI procedures themselves have revealed some of the network's problems.

Once available, analysis maps are also useful for a variety of operational and practical applications, such as forecast verification, environmental monitoring, land and water management, heatwave warnings, fire prevention and as a support for civil protection authorities. Furthermore, a reliable analysis procedure is a powerful tool for the data quality assurance system of any observational network.

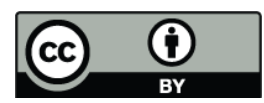

Correspondence to: C. Lussana

(c.lussana@arpalombardia.it) 


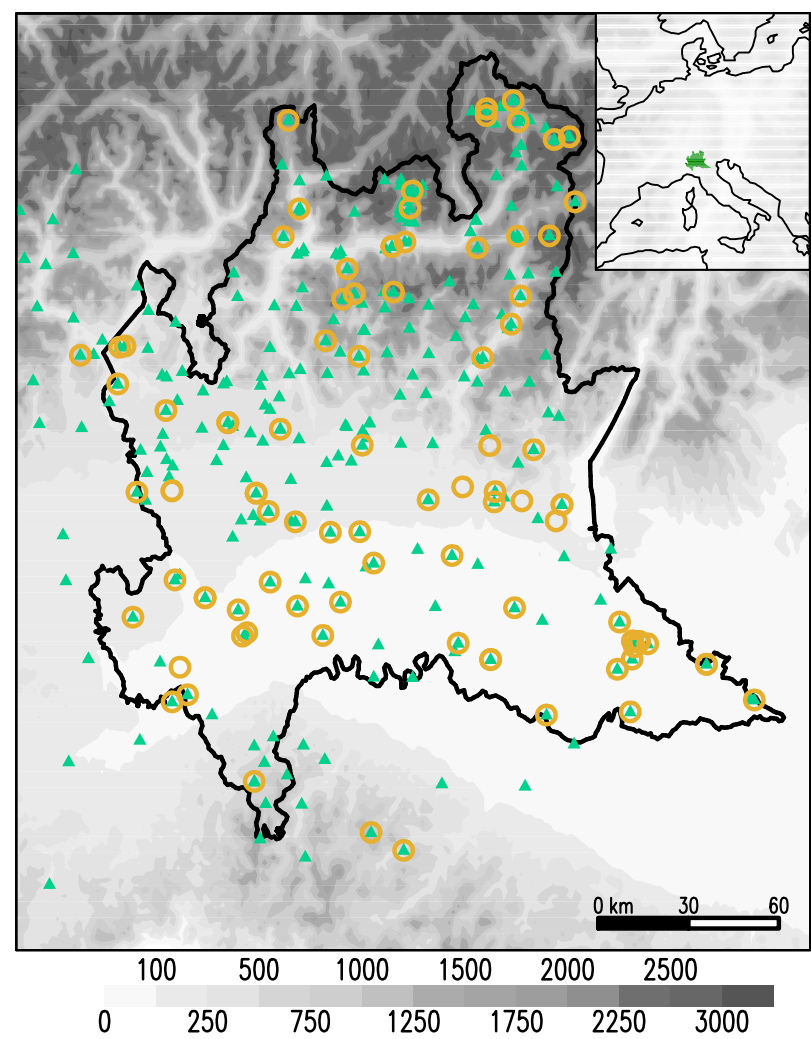

Figure 1. Orography and station locations in the domain. Triangles: raingauges. Circles: anemometers. The bold black line is the administrative boundary. The inset shows the geographical location of Lombardy (Italy), longitude 8.5 to $11.5^{\circ} \mathrm{E}$, latitude 44.6 to $45.7^{\circ} \mathrm{N}$.

\section{Optimal Interpolation schemes}

The statistical interpolation scheme used for this work is described in Uboldi et al. (2008), where it is applied to temperature and relative humidity. Generally, OI schemes use an observation independent background field. This scheme uses instead a 3-D background obtained by observations detrending; this field is representative of the larger scale captured by the network. The present manuscript describes the evolution of the OI scheme and its application to other meteorological quantities. It is worthwhile remarking that the OI scheme described in Uboldi et al. (2008) can also make use of an independent background, as it is done here for precipitation.

Table 2 summarizes the choices made in OI implementation for the variables treated in this work. All the spatial correlation functions used are isotropic except for the improved OI algorithm for temperature. The last three columns of Table 2 report the values for $D_{h}, D_{z}$ and $\varepsilon^{2}$. The de-correlation length scales in the horizontal direction and in the vertical direction, $D_{h}$ and $D_{z}$ respectively, are used in the background error spatial correlation functions to determine the volume
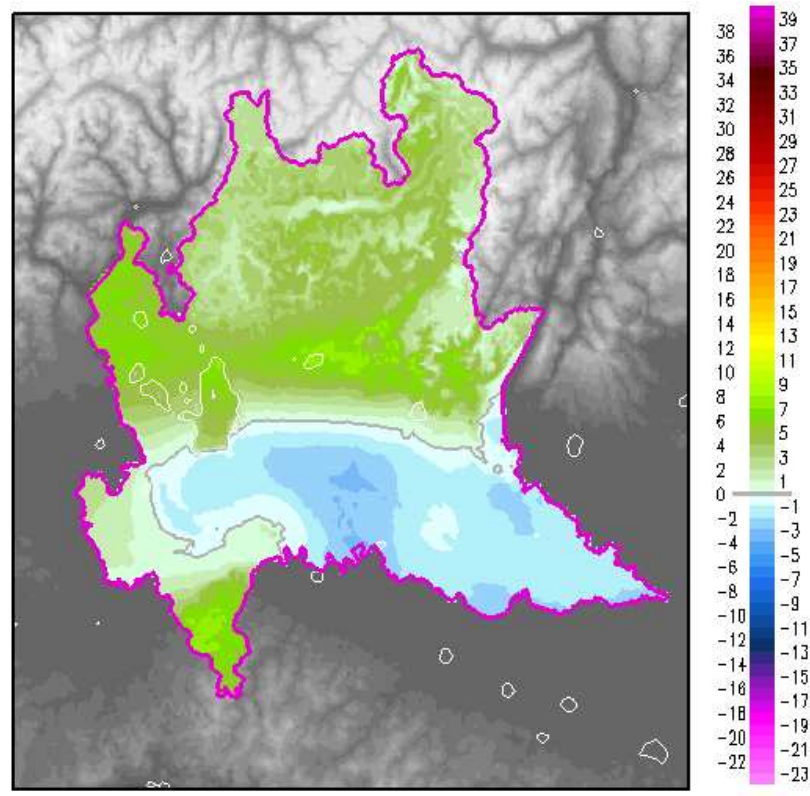

Figure 2. 20 January 2006, 12:00 LT (Local Time=UTC+1). Temperature analysis (unit ${ }^{\circ} \mathrm{C}$ ). The isoline $0{ }^{\circ} \mathrm{C}$ is shown in gray; the white contours mark urban areas.

influencing the analysis at each point inside the domain. The $\varepsilon^{2}$ parameter is defined as the ratio between observation and background uncertainties.

The choices regarding the background must be variable dependent, and are also summarized in Table 2 . In the context of statistical interpolation, precipitation must be regarded as a variable apart from the others because of its specific statistical properties. The OI implementation used in this work combines raingauge measurements and the M. Lema radar-derived Best Estimate of Precipitation rate at the ground (BEP; Joss et al., 1998). Due to the extremely discontinuous nature of the precipitation field, the availability of a background from radar data is very important in reconstructing the analysis field. An effort is made to integrate the two sources of information without degrading them.

For all the other variables, the choice is to build a "pseudo" background field using the data themselves: a least-square minimization procedure is applied at each observation time and the background is calculated as a linear function of the spatial coordinates. For temperature, relative humidity and wind a change in the vertical derivative is allowed, because of frequent decoupling between the atmospheric flow in the Po plain and the flow in the other regions of the domain. Such a background represents the main spatial trends detected by the observations. It is worth remarking that this "pseudo" background field is not suggested here in substitution of a model field. Instead, because a model field may be for various reasons unavailable, the "pseudo" background is meant as a viable alternative that makes use of the only available 
Table 1. Summary of OI implementations for each variable. For a detailed description of the parameters see also Uboldi et al. (2008). $D_{h}$ and $D_{z}$ are the de-correlation length scales in the horizontal direction and in the vertical direction used in the spatial correlation functions; $\varepsilon^{2}$ is the estimated ratio between the variances of observation and background errors (for wind intensities between 5 and $10 \mathrm{~ms}^{-1}$ the $\varepsilon^{2}$ value is interpolated linearly between 0.1 and 0.5 ). A dew-point temperature observation $(*)$ is obtained combining temperature and relative humidity observed at the same station.

\begin{tabular}{|c|c|c|c|c|c|}
\hline $\begin{array}{l}\text { variable } \\
\text { (hourly values) }\end{array}$ & background & $\begin{array}{l}\text { spatial correlation } \\
\text { function }\end{array}$ & $\begin{array}{c}D_{h} \\
(\mathrm{Km})\end{array}$ & $\begin{array}{c}D_{z} \\
(\mathrm{~m})\end{array}$ & $\begin{array}{l}\varepsilon^{2} \\
(-)\end{array}$ \\
\hline temperature (version 1$)$ & main spatial trends present in the fields & 3-D isotropic & 20 & 500 & 0.5 \\
\hline temperature (version 2) & and detected by the observations & 3-D anisotropic & 20 & 500 & 0.5 \\
\hline $\begin{array}{l}\text { relative humidity } \\
\text { (dew-point temperature) }\end{array}$ & $\begin{array}{l}\text { main spatial trends present in the fields } \\
\text { and detected by the observations }(*)\end{array}$ & 3-D isotropic & 30 & 600 & 0.5 \\
\hline $\begin{array}{l}\text { wind vector } \\
\text { (w) }\end{array}$ & $\begin{array}{l}\text { main spatial trends present in the fields } \\
\text { and detected by the observations } \\
\text { ( } u \text { and } v \text { independently) }\end{array}$ & 3-D isotropic & 30 & 600 & $\begin{array}{l}\cdot 0.5 \text { if }|\mathbf{w}|<5 \mathrm{~m} / \mathrm{s} \\
\cdot \text { linear interpolation } \\
\text { if }(5<|\mathbf{w}|<10 \mathrm{~m} / \mathrm{s}) \\
\cdot 0.1 \text { if }|\mathbf{w}|>10 \mathrm{~m} / \mathrm{s}\end{array}$ \\
\hline pressure & $\begin{array}{l}\text { main spatial trends present in the fields } \\
\text { and detected by the observations }\end{array}$ & 2-D isotropic & 40 & - & 0.5 \\
\hline precipitation & M.Lema radar BEP & 2-D isotropic & 10 & - & 0.05 \\
\hline
\end{tabular}

information. Besides, a model-independent analysis can be a convenient choice for studying network's characteristics, and in the case of model verification studies.

In Uboldi et al. (2008) the OI implementation for temperature and relative humidity is described. With respect to that work, here, in order to account for the urban heat island effect, some anisotropy is introduced in the spatial correlation functions for temperature. Urban (grid point/station) locations are decorrelated from non-urban locations depending on the land use in their surroundings. In principle, such a procedure can be extended to other variables.

The interpolation scheme constrains the wind vector to be locally tangent to the grid orography, by making its normal component vanish. The background field is obtained by detrending the zonal and the meridional wind observations independently. Finally, wind observations with a module greater than $10 \mathrm{~m} \mathrm{~s}^{-1}$ are assumed to be more reliable than weak wind observations, influenced by meandering.

For precipitation, the assumption of Gaussian pdf for observation and background errors, implicit in the OI, is very far from reality. In particular, when the observations or the background have zero value then the analyzed field must be exactly zero, while if the reported values for observations or background are positive then the interpolation scheme must always reconstruct positive analysis values. The interpolation procedure must be able to correctly describe both behaviours. For each grid point, the Integral Data Influence (IDI; Uboldi et al., 2008) value computed by only using zero precipitation observations is compared with the IDI value computed by only using positive precipitation observations. Where the "zero-rain" IDI prevails, the analysis value is set to zero. Elsewhere, positive values are interpolated from (positive) observations.
All observations of temperature, relative humidity, wind and pressure are hourly averages, precipitation observations are hourly cumulated values.

\section{Test cases}

The characteristics of the interpolation scheme are shown by using test cases that present strong gradients in the variables' fields. Strong gradients stress the interpolation scheme, evidencing the spatial scales that it is able to reproduce. The meteorological situations chosen -a persistent fog situation, two foehn cases and two precipitation cases- are also relevant for civil protection and economical activities.

\subsection{Fog in the Po Plain}

This test case refers to a winter case of high pressure subsidence causing persistent fog in the Plain (see Fig. 3). The fog, of radiative origin, is associated with a marked groundbased inversion that is well reproduced in temperature and relative humidity fields as an intense gradient in the plain area. The correspondence between the limit of the cloudy area in the meteosat image, a completely independent source of information, and the gradients in the analyzed fields is satisfactory. The fields of wind and atmospheric pressure reduced to the mean sea level, not shown here, exhibit the weak gradients expected in such a situation.

This test case is also used to show the effect of the improved OI scheme for temperature (version 2 in Table 2) with anisotropic correlation functions taking into account urban land use, as described in Sect. 2. It is well known that stations located in densely populated urban areas are influenced by the urban heat island and this is the case for the Milan 

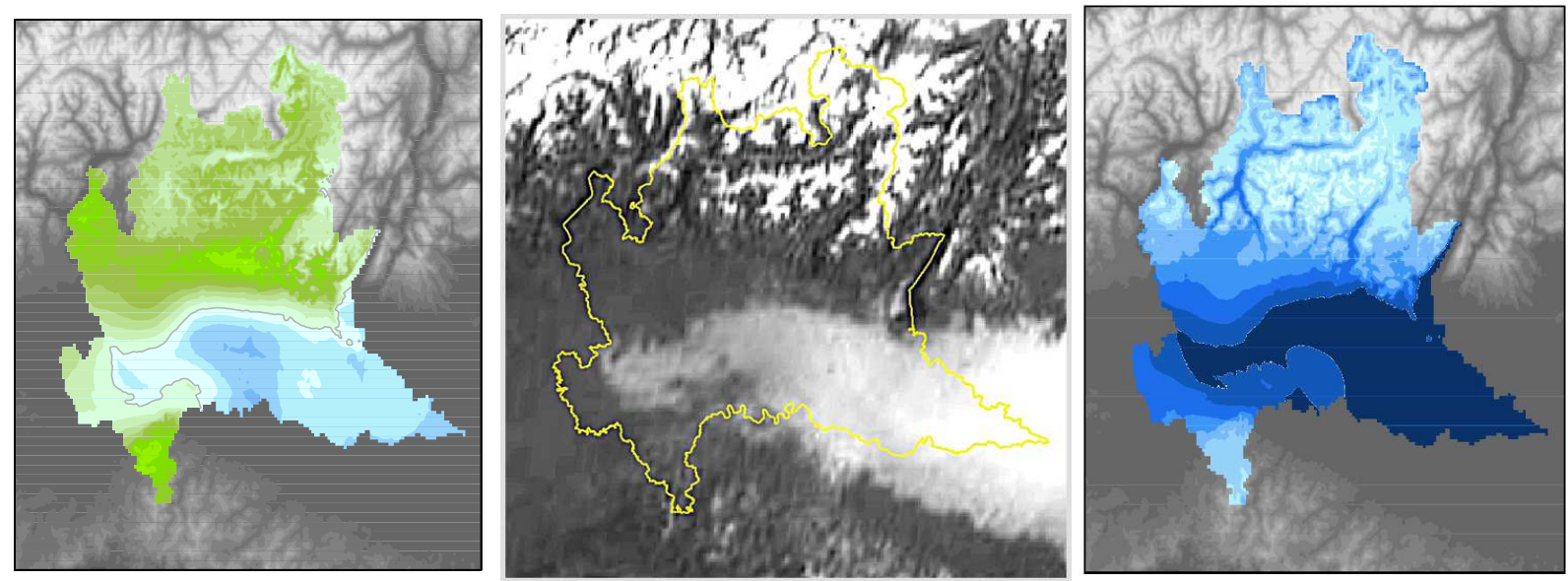

Figure 3. 20 January 2006, 12:00 LT. Left: Temperature. Center: Meteosat-8 Channel 12 (HRV) image. Right: relative humidity (unit \%). The temperature scale is the same as in Fig. 2.
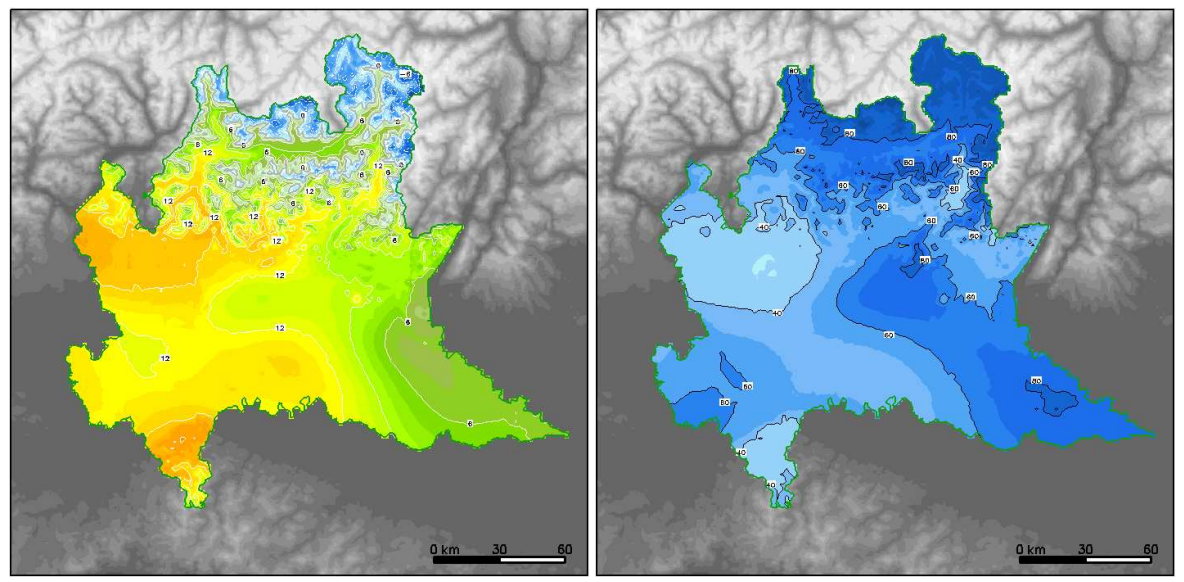

Figure 4. 21 January 2005, 12:00 LT. Left: temperature. Right: relative humidity. See Figs. 2 and 3 for temperature and relative humidity scales, respectively.

area, in the western part of the region. By integrating land use information in the OI scheme, it is possible to recognize and decorrelate urban from non-urban locations. The final effect can be seen by comparing the left panel in Fig. 3 with Fig. 2 in the Milan area. A careful inspection of the meteosat picture shows better agreement with the field in Fig. 2, especially for the Milan area, and a quantitative diagnostics using Cross Validation (CV) scores confirms this qualitative evaluation.

\subsection{Foehn cases}

\subsubsection{January 2005}

The first case, well documented on-line (Eumetsat, 2008), refers to 21 January 2005. The Alps are under the influence of a strong northerly flow with marked stau cloudiness on the main range; the southern slopes and the Po valley are cloud free with strong and gusty foehn winds, and local heating due to adiabatic compression. The observational network has in this case sufficient spatial resolution to measure these local phenomena. As it can be seen from Fig. 4, the warming in the north-west and the correspondent minimum in relative humidity are correctly reconstructed by the analysis. The wind analysis shows a strong intensification, which is well correlated with the other independently analyzed fields (not shown here). 

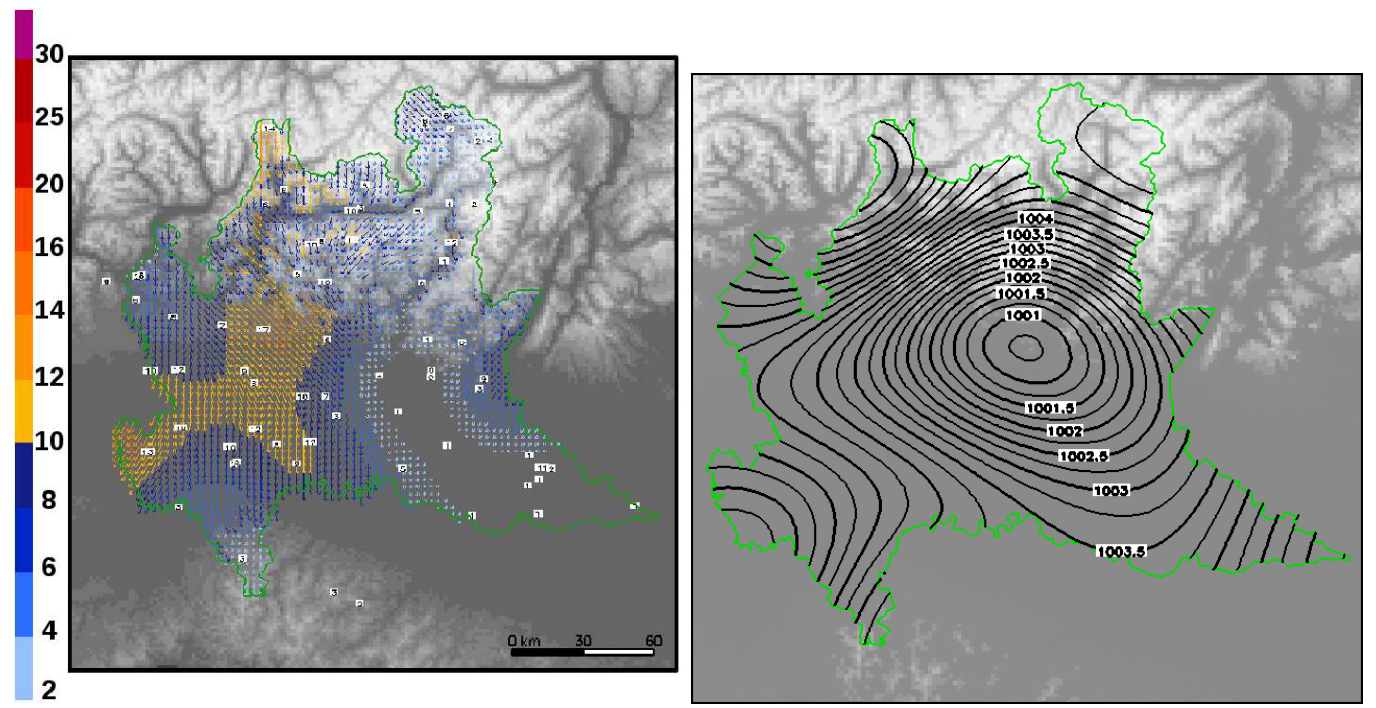

Figure 5. 12 March 2006, 08:00 LT. Left: wind vectors (unit $\mathrm{m} \mathrm{s}^{-1}$; white boxes contain observations and mark station locations). Right: pressure (reduced to the mean sea level; unit hPa).

\subsubsection{March 2006}

The meteorological situation for the second foehn case 12 March 2006 - is similar to the previous one. However, in this case the eastern part of the region is still under the influence of a cyclonic circulation. Very low temperature values were observed in the mountain areas to the northeast, and light snowfall occurred during the morning in the southeastern plain. As can be seen in Fig. 5, the wind field pattern is in agreement with the analyzed pressure gradient; the wind intensity maxima correctly correspond to the dry and warm areas in the temperature and relative humidity analysis (not shown here). It is worth remarking that all the variables are analyzed independently: their consistency is a qualitative confirmation that the OI does not introduce large errors.

\subsection{Precipitation cases}

The results for OI of cumulated precipitation are presented in two very different cases: a case of convective precipitation and a case of stratiform precipitation. Convective and stratiform precipitation have different spatial and temporal coherence, but in both cases the integrated field retains the good features of raingauges observations and post-processed radar background information. The realistic appearance of the $24 \mathrm{~h}$ cumulated fields also shows that any systematic error introduced by the interpolation algorithm must be of small amplitude. In fact, even summing-up many precipitation fields, unrealistic features do not appear.

In order to show the characteristics of the integration of the available information, the precipitation analysis fields for the test cases chosen are compared with the OI of raingauges observation only and with the M. Lema best estimate of precipitation rate at the ground (Joss et al., 1998).

\subsubsection{Convective precipitation}

Convective precipitation is characterized by small horizontal scales and high vertical extension of the precipitating volume. As can be seen in Fig. 6, in this case the radar estimate of the rain field (center panels) is more realistic than what can be obtained with raingauges only (leftmost panels). In the latter, the spatial pattern is clearly mainly determined by the station distribution and the symmetrical correlation functions. The analysis in the rightmost panels, integrating the two sources, maintain the radar's realistic features.

By cumulating the analysis fields over $24 \mathrm{~h}$, the peak of precipitation observed in the radar estimate is correctly conserved in the integrated map.

\subsubsection{Stratiform precipitation}

A stratified precipitation case, of frontal origin, is represented in Fig. 7. In such cases the radar signal may be strongly attenuated, especially in areas far from the radar site (as the north-eastern area of the domain, central panels). The raingauges measurements, where available, allow in these cases a better reconstruction of the precipitation field than what can be obtained by radar estimation alone. The point-wise observations are in this case more representative of an area because of the larger spatial scales that characterize stratiform precipitation. 

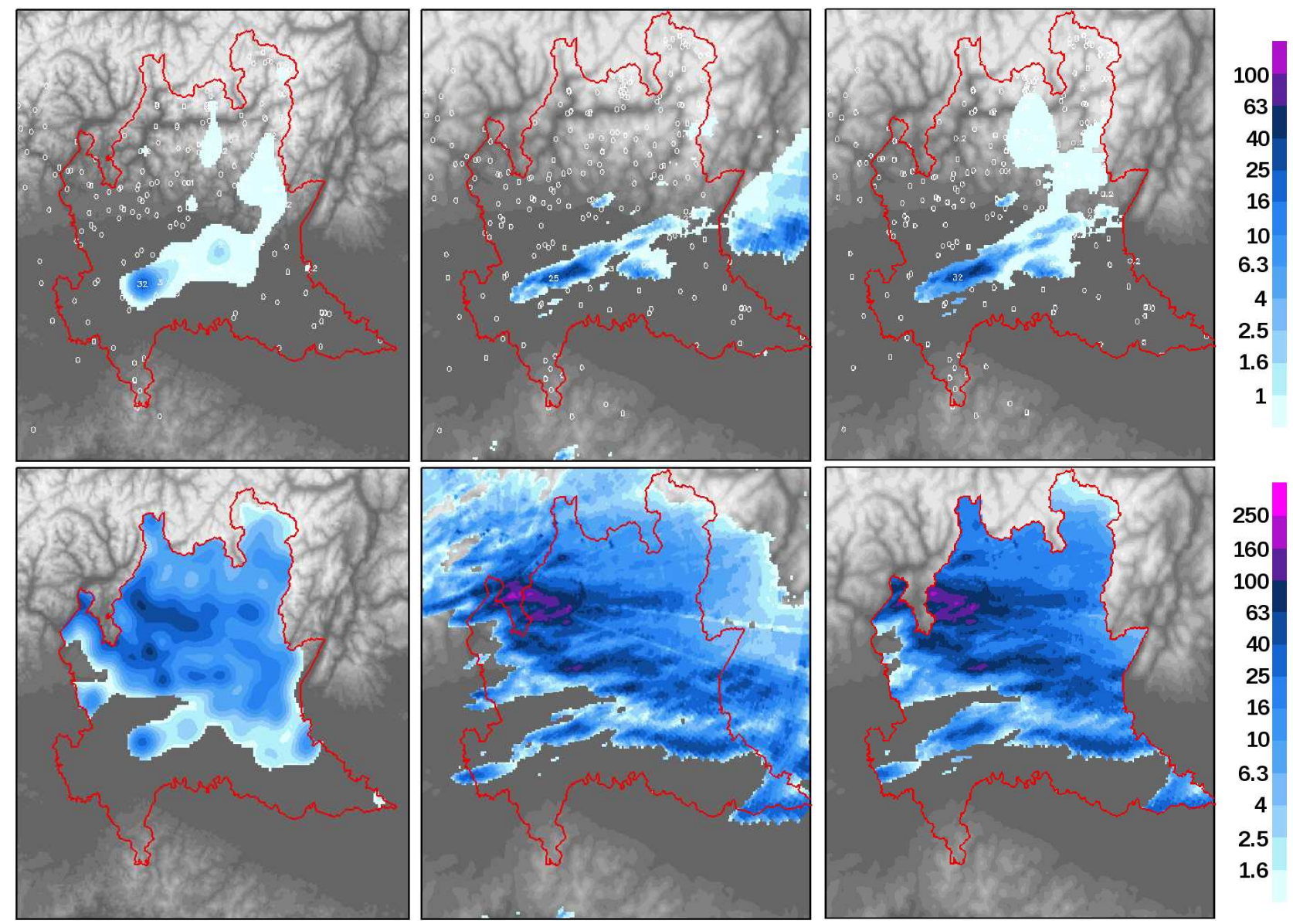

Figure 6. 24 August 2006. Convective precipitation case. The panels above show 1-h precipitation (23:00 LT; unit $\left.\mathrm{mm} \mathrm{h}^{-1}\right) \mathrm{while}$ panels below show 24-h cumulated precipitation (unit $\mathrm{mm} \mathrm{day}^{-1}$ ). Left: analysis field obtained by using raingauges only. Center: M. Lema radarderived best estimate of precipitation rate at the ground. Right: integration of both informational sources. The observed values reported in hourly analysis mark station locations.

\section{Cross Validation scores}

The CV score is routinely computed for each analysis time for temperature and relative humidity. The CV score represents an estimate of the analysis error, based on the idea that each observation is used as an independent verification of the analysis field. The CV score distribution for temperature has been computed for the entire 2006: the overall median is $1.45^{\circ} \mathrm{C}$ and the interquartile range is $0.50^{\circ} \mathrm{C}$. By grouping stations according to the IDI, stations belonging to dense areas of coverage has a CV score distribution median less than $1^{\circ} \mathrm{C}$. Largest errors are more probable for isolated stations with the third quartile having a value close to $2^{\circ} \mathrm{C}$. In any case, the median is always larger than $0^{\circ} \mathrm{C}$ because local scales affecting the observation are filtered out by the interpolation.

The same diagnostic is computed for relative humidity: the median for the year $2006 \mathrm{CV}$ score distribution is $10.4 \%$ and the correspondent interquartile range is $2.45 \%$. However, it must be remembered that, in ARPA Lombardia's meteorological network, the spatial distribution of hygrometers is less dense than the distribution of thermometers.

\section{Conclusions}

An Optimal Interpolation (OI) scheme for the different variables measured by surface weather stations has been here presented. Given the characteristics of this OI implementation, the analysis fields - with the exception of precipitation depend only on point-wise observations. The method is then widely applicable, model-independent and particularly well suited for interpolation of observations from high-density automatic networks, being also robust and efficient.

The presented scheme has been running daily for over three years in ARPA Lombardia's weather service, producing 

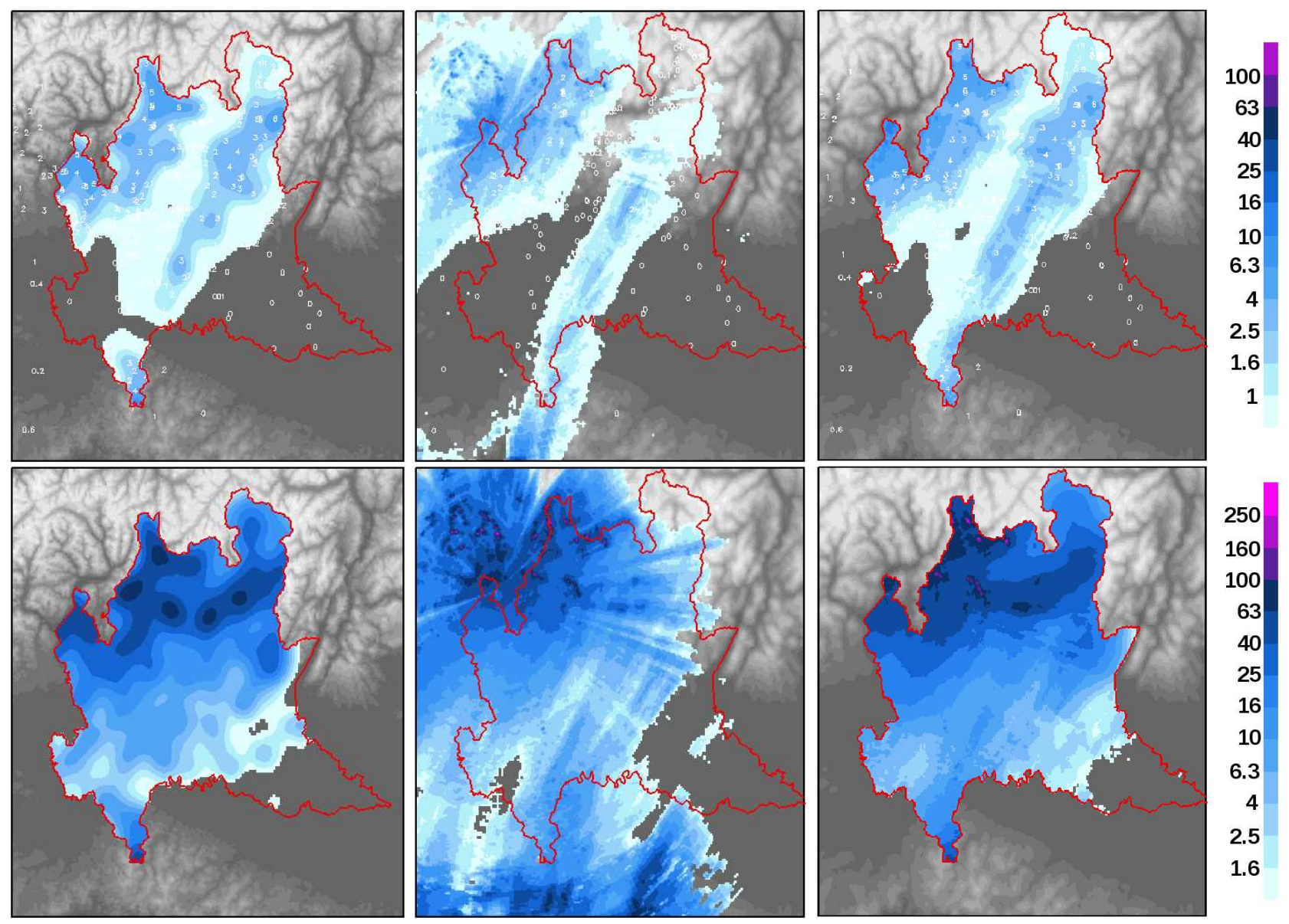

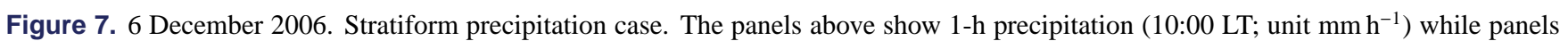
below show 24-h cumulated precipitation (unit $\mathrm{mm} \mathrm{day}^{-1}$ ). Left: analysis field obtained by using raingauges only. Center: M. Lema radarderived best estimate of precipitation rate at the ground. Right: integration of both informational sources. The observed values reported in hourly analysis mark station locations.

satisfactory hourly maps of several variables. The analysis, originally created as a support for forecasting activities, are used today for a variety of purposes (water budget estimates, verification, data quality control, air quality, fire prevention). The diagnostic results presented in Sect. 4 offer a first quantitative indication of the reliability of the analysis fields, which, though still at a preliminary stage, is also quite promising.

Despite the presence of important representativity errors and the complex topography of Lombardy, the observations of the high-resolution local network do provide useful information that is correctly recovered by the interpolation scheme implemented. This result was not so obvious at the beginning of this work, and doubts were mainly motivated by a lack of knowledge of the network reliability. An important result of this work is the better knowledge on reliability and errors of the observational network. This allows for more reasoned choices of the parameters relevant in an OI imple- mentation, and gives a strong feedback to quality assurance and network management procedures.

At present the characterization of observing stations in the OI scheme only depends on their geographical coordinates, with the exception of temperature and relative humidity analysis. These fields have shown improvement after including urban heat island effects, by means of land use information. Further test will be carried out on possible exploitation of other land use and topographic information known to be linked with local effects (e.g. distance from water bodies, slope and aspect,...).

Care must be given when further decorrelating stations that do not exhibit the same properties, as this decreases the average Integral Data Influence value: each change must be evaluated through test cases and quantitative diagnostics before its operational implementation. 


\section{References}

Daley, R.: Atmospheric Data Analysis, Cambridge University Press, 1991.

Eumetsat: Strong North Foehn over the Alps (21 January 2005), http://oiswww.eumetsat.org/WEBOPS/iotm/iotm/ 20050121_foehn/20050121_foehn.html, 2008.

Gandin, L. S.: Objective Analysis of Meteorological Fields, Gidromet, Leningrad. English translation by Israeli Program for Scientific Translations, Jerusalem, 1963.
Joss, J., Schadler, B., Galli, G., Cavalli, R., Boscacci, M., Held, E., Bruna, G. D., Kappenberger, G., Nespor, V., and Spiess, R.: Operational Use of Radar for Precipitation Measurements in Switzerland, Verlag der Fachvereine Hochschulverlag AG an der ETH Zurich, 1998.

Kalnay, E.: Atmospheric Modeling, Data Assimilation and Predictability, Cambridge University Press, 2003.

Uboldi, F., Lussana, C., and Salvati, M.: Three-dimensional spatial interpolation of surface meteorological observations from highresolution local networks, Meteorol. Appl., 15, 331-345, 2008. 